1985 - ACM ANNUAL CONFERENCE

\title{
Computer-Chess Session
}

Call for Papers

The announcement below reached the Journal while the December 1984 issue was in print. Due to its late arrival, the best we could do was to queue the announcement for the March 1985 issue. Unfortunately, the message thereby ceased to be an invitation. Nevertheless, we publish the call for papers in order to attend readers to a possibility which, with details duly amended, almost certainly will materialize in 1986 too.

A technical session on computer chess, consisting of refereed papers, will be part of ACM 1985. Papers in all areas of computer chess will be considered. Papers should be no more than 2000 words in length. Authors should submit 4 copies of their papers by February 15, 1985 to

$$
\begin{aligned}
& \text { Dr. Judith D. Schlesinger } \\
& \text { Program Cha1r, ACM' } 85 \\
& \text { P.0. Box } 24102 \\
& \text { Denver, Colorado } 80224
\end{aligned}
$$

Late submissions, to be received before March 15, 1985, should be sent to

$$
\begin{aligned}
& \text { Dr. T.A. Marsland } \\
& \text { Dept. of Computing Science } \\
& \text { University of Alberta, } \\
& \text { Edmonton, Canada T6G } 2 \mathrm{H} 1
\end{aligned}
$$

Authors will be notified of acceptance by April 15 and camera-ready copies must be received by June 15 .

$$
\text { ACM'85 - October 14-16, Denver Colorado }
$$

